\title{
MULTI RESPONSE OPTIMIZATION OF INCONEL 625 WIRE ARC DEPOSITION FOR DEVELOPMENT OF ADDITIVE MANUFACTURED COMPONENTS USING GREY RELATIONAL ANALYSIS (GRA)
}

\author{
D. T. Sarathchandra*, M. J. Davidson \\ Department of Mechanical Engineering, National Institute of Technology Warangal, \\ India
}

Received 21.11.2020

Accepted 10.02.2021

\begin{abstract}
The paper investigates the multi response optimization of single bead deposition characteristics, which affects the additive manufactured structures in later stages of multi layered depositions. Inconel 625 single beads were deposited using the cold metal transfer (CMT) based on Wire Arc Additive Manufacturing (WAAM). The bead width, bead height, penetration depth, and microhardness of the fusion region are considered for the decision criteria models. Grey relational analysis (GRA) is used to solve the multi criteria optimization problem. Analysis of variance has been performed to quantify the effects of the parameters on grey relational grade (GRG). From the GRA, it is observed that the combined performance of minimum bead width, minimum bead height, maximum penetration depth, and maximum microhardness at parameter setting of $110 \mathrm{Amps}$ current, $0.4 \mathrm{~mm} / \mathrm{sec}$ weld speed, and $4 \mathrm{~mm}$ standoff distance.
\end{abstract}

Keywords: wire arc additive manufacturing; cold metal transfer process; multi response optimization; grey relational analysis.

\section{Introduction}

Inconel 625 offers excellent mechanical strength and corrosion resistance at high temperatures and in a high-pressure environment. Hence, Inconel 625 superalloy is primarily used in marine, nuclear applications. Even though many production methods fail to manufacture and machine Inconel-based superalloys due to their high hardness and hence challenging to machine with standard cutting tools and materials, which leads to

${ }^{*}$ Corresponding author: D.T. Sarathchandra, sarathchandradongari @ gmail.com, sarathchandra999@gmail.com 
increased production costs. Therefore, Additive manufacturing (AM) can be a cost effective and feasible production method for superalloys [1]. Since the laser-assisted AM processes are low energy efficient, wire arc-based deposition processes are emerged, which are capable of $80-90 \%$ energy efficiency. The primary heat source to melt the materials is obtained from an electric arc which is developed due to the potential difference between the wire (feedstock) and the component being formed.

Wire and arc additive manufacturing (WAAM) belongs to the directed energy deposition process, which uses electrical arc as energy source and wire as feedstock. WAAM can be attained by processes like Gas Metal Arc Welding (GMAW) [2], Gas Tungsten Arc Welding (GTAW) [3], and Plasma Arc Welding (PAW) [4]. There are numerous advantages for WAAM over laser-assisted and plasma-assisted additive manufacturing processes in terms of the capital cost of machines, material flexibility. The cold metal transfer (CMT) process is considered to advance the GMAW process with lower heat input and spatter than other arc welding methods [5]. The key factor involved in CMT technology is the automatic wire feed controller. The reciprocated wire feed mechanism was incorporated with an electrical process which in turn arc initiation and short circuiting will be synchronized by the electrical controller.

In the present study, the cold metal-based wire arc deposition process is used to prepare the samples. The single bead depositions, which are treated as the building blocks of any additive manufactured components, influence the mechanical and metallurgical properties of the additive manufactured components. The depositions should have optimum bead characteristics as well as mechanical strength. Hence, multi decision criteria optimization is required to establish better processing conditions through which quality tracks or beads are made. The same conditions can be used, and good quality additive manufactured components are produced with a multi pass, multi-track depositions.

Many input factors contribute directly or indirectly to the deposition structures in the CMT process. These include input power, weld speed, wire feed rate, standoff distance, inert gas flow rate, path planning, deposition strategies, etc. It is too difficult to experiment with all the parameters and levels. Hence, the design of experiments is used to reduce the number of experiments without biasing the effect of the parameters on the response.

Response Surface Methodology (RSM) accurately predicts the interaction and square terms in the response model, whereas the Taguchi design of experiments is used only for linear interactions. The effect of process parameters on responses can be visualized in 2D and 3D surfaces contours in RSM. The grey relational analysis was used to evaluate the multi response optimization by giving the weights to the responses. Deng proposed grey relational analysis (GRA) in 1989. The Grey relational assessment is a technique of evaluating the degree of similarity between the sequences through grading. The Grey relation evaluation concepts have drawn significant interest among researchers. Some researchers worked to optimize the multi objective optimization using GRA [6]. Different multi attribute methods, namely AD, TRIZ, Fuzzy, Grey relational analysis, and feasibility approaches, are demonstrated by $W u$ et al. [7]. Design of experiments(Taguchi designs and Response surface Designs) are coupled with GRA has been performed by many researchers for manufacturing methods such as castings, forming, welding, and machining applications like turning, milling, drilling, etc. Tzeng et. al. studied turning 
process optimization using grey relational analysis. L9 Taguchi design was used for the experimentation. The average roughness and roundness of the machined samples are taken into consideration for multi objective optimization. It was observed that the depth of cut and cutting speed are the most influencing parameters for average roughness and maximum roundness [8]. Prakash utilized the grey relational analysis approach for multi attribute optimization of turning the Aluminum composite. Results show that cutting feed has a remarkable effect on the multi attribute response characteristics [9]. Rajeswari et al. studied multi objective optimization of milling process using RSM coupled with GRA. Maximum material removal rate and minimum surface roughness, tool wear, cutting force are considered for the study. Box-Behnken Design was used to conduct the experiments on Aluminium 7075 composites with $\mathrm{SiC}$ and Alumina s reinforcements. And it was observed that the appropriate optimal setting parameters from GRA produce low cutting forces, less wear with fine surface finish, and maximum material removal rate [10]. Lu et $a l$. explored the multiple performances of high speed end milling of tool steel using grey relational analysis. Metal removal rates and tool life are considered for the study. The weights for the responses are evaluated by principal component analysis. This method effectively acquires the optimal setting combination of milling characteristics [11]. Xu et al. used Taguchi based grey relational analysis on tailor-welded blanks (TWBs) to improve the performance of the joint. The peak crashing force (Fmax), the total weight (Mass), and the total energy absorption (EA) are chosen for multi performance analysis. Results demonstrate that the grey correlation of the structure enhances the crashworthiness of TWBs [12]. Srirangan et al. investigate Incoloy $800 \mathrm{HT}$ welded with tungsten inert arc welding process and multi objective optimization of tensile strength, yield strength, and impact strength using grey relational analysis [13]. Chen et al. performed grey relational analysis for $\mathrm{CO}_{2}$ laser machined polymethyl methacrylate plates. The multiple performance study involves surface roughness and transmission ratio concerning the process parameters. This investigation used an L9 orthogonal array to conduct the experiments. The results showed that the gas flow rate has more influence on the performance characteristics [14]. Tamrin et al. investigated multiple quality characteristics of a $\mathrm{CO}_{2}$ laser welded dissimilar material lap joint as a function of welding parameters. A full-factorial experiment is followed for experimentation. Grey relational analysis (GRA) is used to determine the optimal setting parameters for the combined responses. ANOVA is carried out to know the influential parameters and found that weld speed has more contribution to predicting the responses [15]. Shanmugarajan et al. applied GRA to find out the optimum parameter settings for creep strength ferritic steels used for high temperature applications, which are process in $\mathrm{CO}_{2}$ laser welding, and closely predict the experimental values [16]. Pan et al. studied titanium alloy plates joined with Nd: YAG laser welding and determine the multiple quality characteristics optimization using Taguchi coupled with grey relational analysis. GRA successfully detraining the optimum parameter which satisfy the multiple performance characteristics. This new approach improves the performance of the welded joints [17]. Prajapathi et al. investigated the optimization of performance characteristics of regulated metal deposition (RMD)welding of stainless steel. Bead width, depth of penetration, and heat-affected zone are considered for the study. An integrated fuzzy system with Taguchi design is used along with the grey relational analysis. From the results, it was observed that voltage is the most influencing parameter than other process parameters to evaluate the multi performance of the RMD process [18]. Tarng et al. use grey relational analysis to solve 
multiple performances of the submerged arc welding process (SAW). Results reveal that the Taguchi-based GRA effectively determined the combination parameter settings for the multiple performances of the process [19].

Even though most of the literature is available on multi objective optimization of conventional manufacturing and machining processes, a few are demonstrated to apply multi decision criteria methods and their effectiveness in the production of additive manufacturing samples and components.

Hence, in the present work, an attempt has been made to investigate multi objective optimization of Inconel 625 bead characteristics deposited by CMT using the RSM coupled with GRA. Three parameters, namely current, weld speed, and standoff distance, are selected to run the experiment. GRA is applied to estimate optimum operating conditions. High current implies high electrode or feed wire melting; thereby, a large amount of heat is available to fuse the wire, resulting in bead shape changes. The bead shape greatly depends on weld speed since material fusion, the formation of the droplet, and thermal cycle detachment happens in seconds. This occurrence depends on weld speed; hence, weld speed is desirable for deposition stability. The torch/nozzle would be away from the deposited surface at a high standoff distance. Accordingly, the arc force will be diminished and tend to spread out so that the bead width and penetration area increases with standoff distance. As the bead width is increased, the deposition material flows on the layered surface, affecting the succeeded layers. Less bead height increases more number of layers to deposit, more the number of layers results in low roughness values. The penetration depth directly affects the bonding strength of the layer interface regions. Hence, the optimum responses are chosen as a minimum bead width, minimum bead height, maximum penetration, and maximum microhardness.

\section{Materials and methods}

\subsection{Material data and experimental method}

Experiments were conducted on Fronius made manual CMT machine TPSI 320I model, attached with in-house developed 3 axis manual controlled work station. While experimenting, the welding torch was held stationary in a vertical position through which filler wire feeding on the system at a fixed angle. At the same time, the Table bed will have 3 axis motions. Argon gas with a flow rate of 10 liters/min was used as a shielding gas supplied from the Cylinder. The schematic diagram of the CMT process was shown in Fig 1. Commercially available Inconel 625 filler wire of $1.2 \mathrm{~mm}$ diameter was used for deposition. The chemical composition of the wire which was certified is as shown in Table 1. Mild steel of size 250 x 250 x $10 \mathrm{~mm}$ was used as the substrate for deposition. Before conducting the experiments, mild steel plates are sandblasted over the surface and cleaned to dry to avoid contaminations.

Table 1. Chemical composition of Inconel 625.

\begin{tabular}{llllllllll}
\hline Elements & $\mathrm{Ni}$ & $\mathrm{Cr}$ & $\mathrm{Mo}$ & $\mathrm{Nb}$ & $\mathrm{Fe}$ & $\mathrm{Al}$ & $\mathrm{Ti}$ & $\mathrm{C}$ & $\mathrm{Mn}$ \\
\hline
\end{tabular}

Percentage Bal. 20-23 8-10 3.15-4.15 Max 5 Max 0.4 Max 0.4 Max 0.1 Max 0.5 


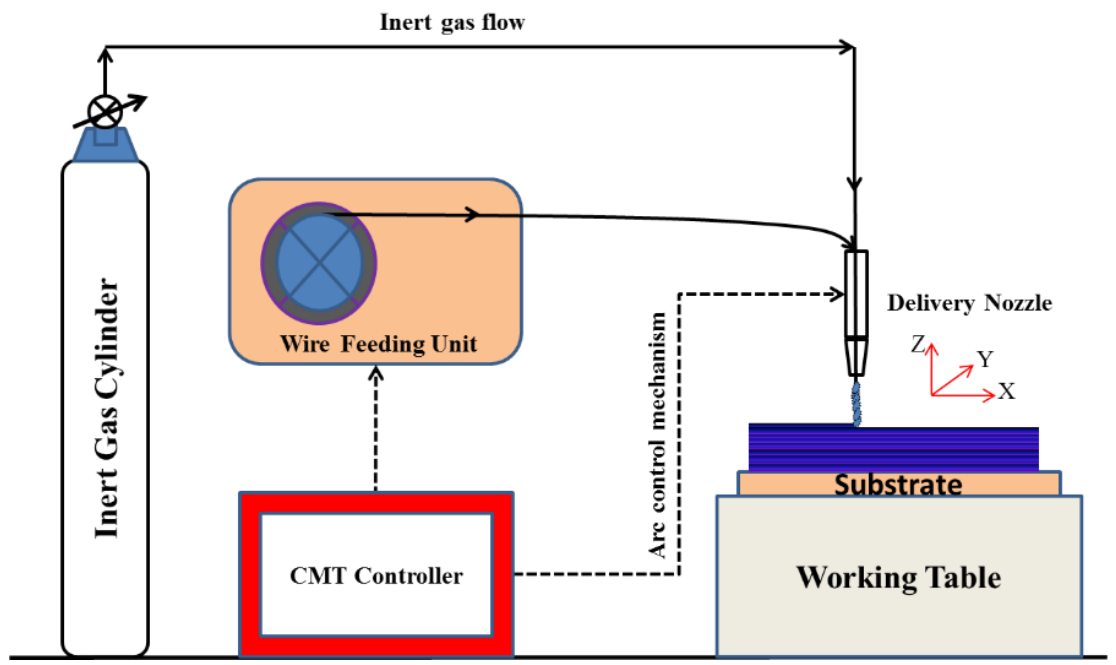

Fig. 1. Schematic diagram of WAAM system with CMT configuration.

Input current (I), welding speed (S), and Stand-off Distance (D) are observed to be the most affecting process parameters on bead characteristics. Parameter ranges were identified by conducting trial experiments. Based on trial experiments and literature research, current, standoff distance, and weld speed are found to be important parameters for experimental design [20]. Table 2 shows the experimental design condition as per the central composite experimental design [21] for 3 parameters and 3 level response surface designs.

\subsection{Grey Relational Analysis}

For both consumers and manufacturers, quality and profitability are critical. The objective of real time situations is multi objective in nature. Hence it is essential to convert a multi optimization problem into a single objective function through statistical approaches. Grey relational analysis is one of them. Dong introduced the grey relational theory [22] in the 1980s. Since then, the grey theory was popular among researchers and scientists to solve the multi decision criteria problems. The steps followed in GRA is

(1) Normalize the data obtained from experiments from zero to one

(2) Grey relational coefficients has to be evaluated from the normalized data

(3) Obtain overall grey relational grade (GRG)

From the GRG, whichever the experimental condition has got Rank 1 is considered to be the optimal setting that satisfies all the objective functions.

The characteristics equations for normalizing the minimization and maximization problems are obtained by using the Eqs. (1) and (2).

$$
x_{i}^{*}(k)=\frac{\max \left(x_{i}^{o} k\right)-x_{i}^{o}(k)}{\max \left(x_{i}^{o}(k)\right)-\min \left(x_{i}^{o}(k)\right)}
$$




$$
x_{i}^{*}(k)=\frac{x_{i}^{o}(k)-\min \left(x_{i}^{o} k\right)}{\max \left(x_{i}^{o}(k)\right)-\min \left(x_{i}^{o}(k)\right)}
$$

Where $x_{i}^{*}(k)$ the sequence data is after normalization $x_{i}(k)$ is the actual response value, $\max \left(x_{i}^{o}(k)\right)$ its maximum value, and $\min \left(x_{i}^{o}(k)\right)$ is the minimum value of the generated data.

After the normalization matrix obtained from the experimental data, Grey relational coefficients are obtained to estimate the relationship between normalized data and actual data and is calculated using the Eqn (3):

$$
\xi(k)=\frac{\Delta_{\min }+\xi \Delta_{\max }}{\Delta o_{i}(k)+\xi \Delta_{\max }}
$$

Where $\Delta o_{i}(k)$ is deviation sequence and is calculated as $\left|x_{i}^{*}(k)-x_{i}^{o}(k)\right| \xi_{\text {is the }}$ distinguished coefficient and the value is ranging between 0 to 1 . In general, it is taken as 0.5 . The next step is to obtain the Grey Relational Grade (GRG) and is defined as

$$
\gamma_{i}=\frac{1}{n} \sum_{k=1}^{n} w_{k} \xi_{i}(k)
$$

Where ${ }^{w_{k}}$ is the weight factor.

\section{Results and discussions}

Inconel 625 single beads were successfully deposited on a mild steel substrate, as shown in Fig 2. The samples were cut in the middle of extracted from the plate. A sample micrograph of the deposition and corresponding bead measurement are depicted in Fig 3. The bead characteristics such as bead width, bead height, and penetration were observed from the micrographs through 3d optical microscope (Make: QASMO optical microscope DIC polarizer, Model: QX4RT) at $1000 \mu \mathrm{m}$ scale. Since additively layered structures, smooth, flat, and thin layers are recommended to deposition successive layers. Hence, the minimum bead width, minimum bead height, and maximum penetration are the desired objectives for the present study. Figure 4 shows a schematic diagram of the bead geometry measurements that are observed from the micrographs. Microhardness testing was conducted on a Vickers microhardness tester with a load of 500 grams. Microhardness values are tested in the deposited area i.e., fusion zone. Four readings are observed, and the average is reported in the results. The RSM experimental design and corresponding responses are tabulated in Table 2 . The experiments were randomly conducted to ensure the results are free from experimental bias. 


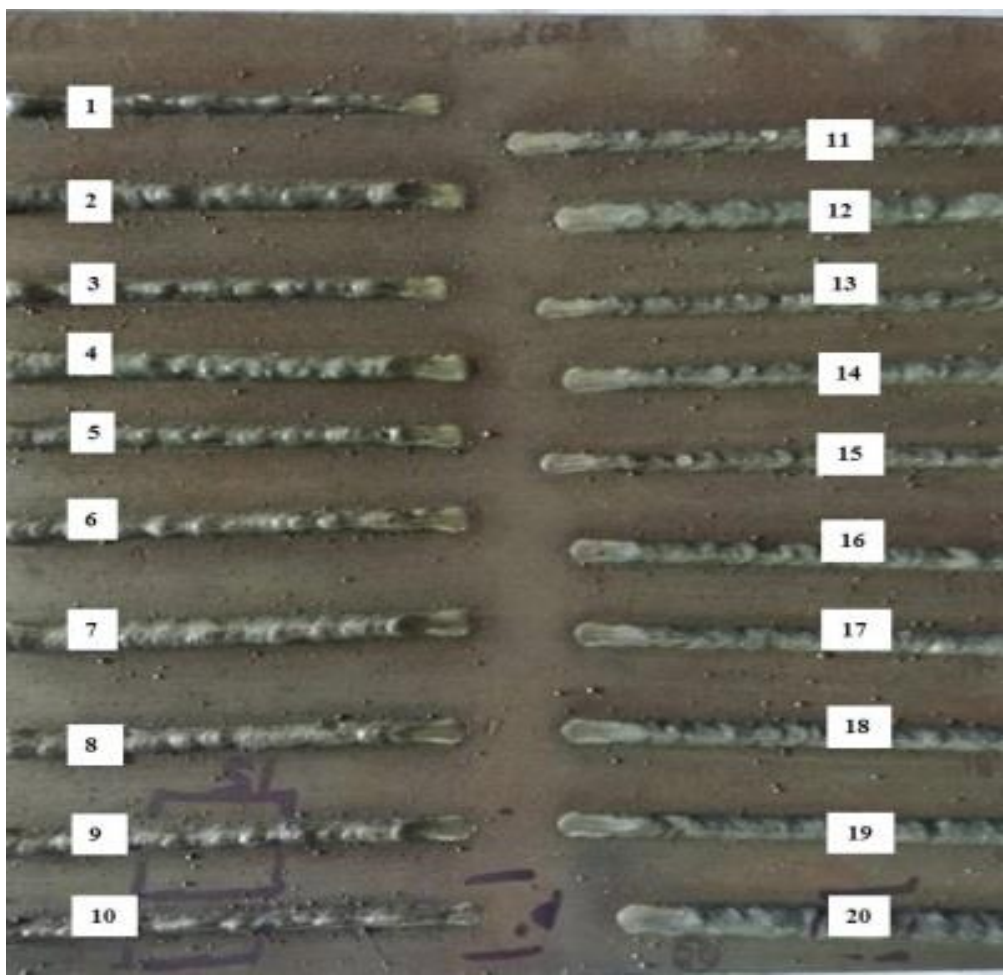

Fig. 2. Inconel 625 deposition clads on a mild steel substrate.

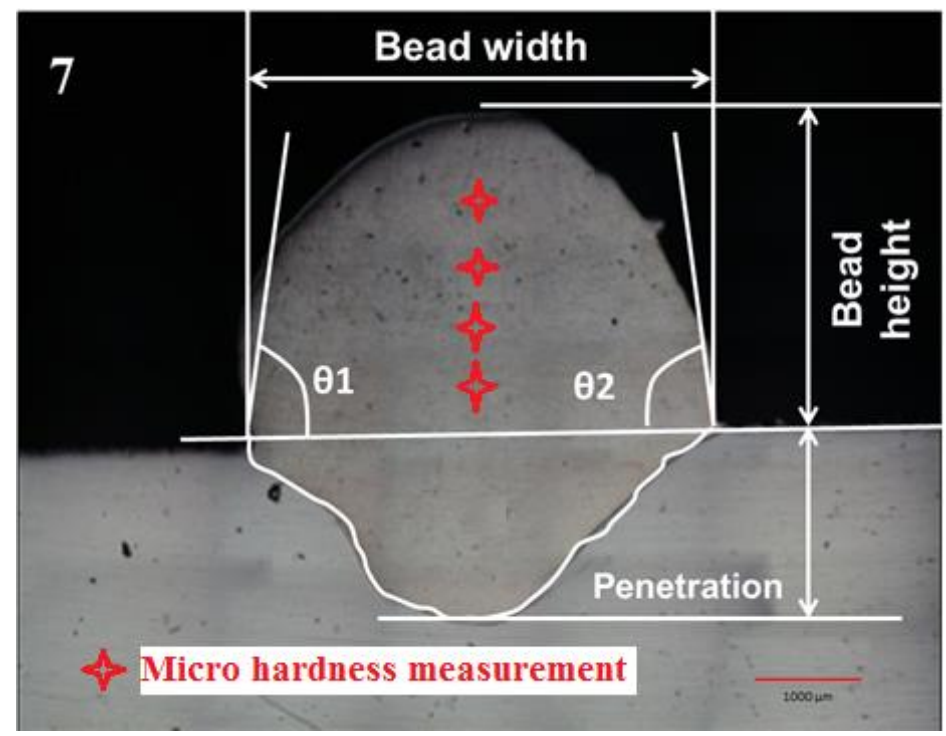

Fig. 3. Bead characteristics measurement. 
Table 2. Experimental conditions and responses.

\begin{tabular}{|c|c|c|c|c|c|c|c|}
\hline \multicolumn{4}{|c|}{ Experimental conditions } & \multicolumn{4}{|c|}{ Responses for multi decision optimization } \\
\hline $\begin{array}{c}\text { Sample } \\
\text { No }\end{array}$ & $\begin{array}{l}\text { Current } \\
\text { (Amps) }\end{array}$ & $\begin{array}{c}\text { Standoff } \\
\text { Distance }(\mathrm{mm})\end{array}$ & $\begin{array}{c}\text { Weld } \\
\text { speed } \\
(\mathrm{mm} / \mathrm{sec}) \\
\end{array}$ & $\begin{array}{l}\text { Bead } \\
\text { Width } \\
(\mathrm{mm}) \\
\end{array}$ & $\begin{array}{c}\text { Bead } \\
\text { Height } \\
(\mathrm{mm}) \\
\end{array}$ & $\begin{array}{c}\text { Penetration } \\
\text { depth } \\
(\mathrm{mm})\end{array}$ & $\begin{array}{c}\text { Microhardness } \\
(\mathrm{VHN})\end{array}$ \\
\hline 1 & 90 & 4 & 0.4 & 3.901 & 3.217 & 1.197 & 225.925 \\
\hline 2 & 100 & 5 & 0.3 & 4.732 & 3.732 & 1.794 & 231.500 \\
\hline 3 & 100 & 5 & 0.3 & 5.164 & 3.734 & 1.419 & 216.750 \\
\hline 4 & 90 & 4 & 0.2 & 5.637 & 4.072 & 1.253 & 222.275 \\
\hline 5 & 100 & 5 & 0.3 & 5.082 & 3.179 & 1.711 & 163.300 \\
\hline 6 & 100 & 5 & 0.3 & 4.833 & 3.531 & 3.531 & 215.750 \\
\hline 7 & 110 & 4 & 0.2 & 2.696 & 2.371 & 0.767 & 215.500 \\
\hline 8 & 110 & 6 & 0.4 & 4.477 & 3.123 & 1.739 & 207.350 \\
\hline 9 & 90 & 6 & 0.2 & 2.653 & 1.935 & 0.786 & 221.325 \\
\hline 10 & 90 & 6 & 0.4 & 3.858 & 3.68 & 1.134 & 226.950 \\
\hline 11 & 110 & 4 & 0.4 & 2.281 & 1.592 & 0.872 & 206.575 \\
\hline 12 & 110 & 6 & 0.2 & 5.912 & 3.868 & 1.775 & 229.625 \\
\hline 13 & 83.67 & 5 & 0.3 & 4.133 & 2.778 & 1.281 & 219.100 \\
\hline 14 & 116.33 & 5 & 0.3 & 5.209 & 3.194 & 1.711 & 205.900 \\
\hline 15 & 100 & 5 & 0.4633 & 4.425 & 2.351 & 1.481 & 216.350 \\
\hline 16 & 100 & 3.367 & 0.3 & 4.643 & 2.951 & 1.668 & 241.050 \\
\hline 17 & 100 & 5 & 0.3 & 4.655 & 2.896 & 1.679 & 218.575 \\
\hline 18 & 100 & 5 & 0.3 & 4.901 & 3.397 & 1.84 & 218.350 \\
\hline 19 & 100 & 6.633 & 0.3 & 4.803 & 3.062 & 1.94 & 208.175 \\
\hline 20 & 100 & 5 & 0.1367 & 3.332 & 1.898 & 0.858 & 230.675 \\
\hline
\end{tabular}

The normalization data calculated from the original responses are presented in Table 3 and followed by the deviation matrix in Table 4 . Since the bead penetration directly affects the successive layers' bonding characteristics, it has given more priority; hence, it has a higher weightage of 0.4. Also, microhardness represents the mechanical strength of the deposition; thus, it has given 0.3 weightage. Bead height and bead width have given a low weightage of each 0.15 . The final grey relational grade (GRG) was evaluated, and the combined GRG with the four responses are presented in Table 5. All the experiments were given ranks based on the GRG grade.

From Table 5, it is observed that experiment no 6 has rank 1 with the highest grade of 0.718 . Hence this condition is treated as an optimal parameter setting that satisfies all four responses. Different parameter settings can be obtained with different weightage combinations. This all depends on the desired performance and application. The 
performance measures will depend on the weightage combination. Different weights can be given to the responses based on the priorities and requirements for the specific applications.

Table 3. Normalized values.

\begin{tabular}{|c|c|c|c|c|}
\hline \multicolumn{5}{|c|}{ Normalization table } \\
\hline $\begin{array}{l}\text { Sample } \\
\text { No }\end{array}$ & $\begin{array}{l}\text { Bead } \\
\text { Width } \\
(\mathrm{mm})\end{array}$ & $\begin{array}{l}\text { Bead } \\
\text { Height } \\
(\mathrm{mm})\end{array}$ & $\begin{array}{l}\text { Penetration } \\
\text { depth }(\mathrm{mm})\end{array}$ & $\begin{array}{l}\text { Microhardness } \\
\text { (VHN) }\end{array}$ \\
\hline 1 & 0.554 & 0.345 & 0.156 & 0.805 \\
\hline 2 & 0.325 & 0.137 & 0.372 & 0.877 \\
\hline 3 & 0.206 & 0.136 & 0.236 & 0.687 \\
\hline 4 & 0.076 & 0.000 & 0.176 & 0.759 \\
\hline 5 & 0.229 & 0.360 & 0.342 & 0.000 \\
\hline 6 & 0.297 & 0.218 & 1.000 & 0.675 \\
\hline 7 & 0.886 & 0.686 & 0.000 & 0.671 \\
\hline 8 & 0.395 & 0.383 & 0.352 & 0.567 \\
\hline 9 & 0.898 & 0.862 & 0.007 & 0.746 \\
\hline 10 & 0.566 & 0.158 & 0.133 & 0.819 \\
\hline 11 & 1.000 & 1.000 & 0.038 & 0.557 \\
\hline 12 & 0.000 & 0.082 & 0.365 & 0.853 \\
\hline 13 & 0.490 & 0.522 & 0.186 & 0.718 \\
\hline 14 & 0.194 & 0.354 & 0.342 & 0.548 \\
\hline 15 & 0.410 & 0.694 & 0.258 & 0.682 \\
\hline 16 & 0.349 & 0.452 & 0.326 & 1.000 \\
\hline 17 & 0.346 & 0.474 & 0.330 & 0.711 \\
\hline 18 & 0.278 & 0.272 & 0.388 & 0.708 \\
\hline 19 & 0.305 & 0.407 & 0.424 & 0.577 \\
\hline 20 & 0.711 & 0.877 & 0.033 & 0.867 \\
\hline
\end{tabular}


Table 4. Deviation sequence matrix.

\begin{tabular}{|c|c|c|c|c|}
\hline \multicolumn{5}{|c|}{ Deviation sequence $\left(\Delta_{\mathrm{oi}}\right)$ table } \\
\hline $\begin{array}{l}\text { Sample } \\
\text { No }\end{array}$ & $\begin{array}{l}\text { Bead } \\
\text { Width } \\
(\mathrm{mm})\end{array}$ & $\begin{array}{l}\text { Bead Height } \\
\quad(\mathrm{mm})\end{array}$ & $\begin{array}{l}\text { Penetration } \\
\text { depth }(\mathrm{mm})\end{array}$ & $\begin{array}{l}\text { Microhardness } \\
\quad(\mathrm{VHN})\end{array}$ \\
\hline 1 & 0.446 & 0.655 & 0.844 & 0.195 \\
\hline 2 & 0.675 & 0.863 & 0.628 & 0.123 \\
\hline 3 & 0.794 & 0.864 & 0.764 & 0.313 \\
\hline 4 & 0.924 & 1.000 & 0.824 & 0.241 \\
\hline 5 & 0.771 & 0.640 & 0.658 & 1.000 \\
\hline 6 & 0.703 & 0.782 & 0.000 & 0.325 \\
\hline 7 & 0.114 & 0.314 & 1.000 & 0.329 \\
\hline 8 & 0.605 & 0.617 & 0.648 & 0.433 \\
\hline 9 & 0.102 & 0.138 & 0.993 & 0.254 \\
\hline 10 & 0.434 & 0.842 & 0.867 & 0.181 \\
\hline 11 & 0.000 & 0.000 & 0.962 & 0.443 \\
\hline 12 & 1.000 & 0.918 & 0.635 & 0.147 \\
\hline 13 & 0.510 & 0.478 & 0.814 & 0.282 \\
\hline 14 & 0.806 & 0.646 & 0.658 & 0.452 \\
\hline 15 & 0.590 & 0.306 & 0.742 & 0.318 \\
\hline 16 & 0.651 & 0.548 & 0.674 & 0.000 \\
\hline 17 & 0.654 & 0.526 & 0.670 & 0.289 \\
\hline 18 & 0.722 & 0.728 & 0.612 & 0.292 \\
\hline 19 & 0.695 & 0.593 & 0.576 & 0.423 \\
\hline 20 & 0.289 & 0.123 & 0.967 & 0.133 \\
\hline
\end{tabular}


Table 4. Grey relational grading and ranking.

\begin{tabular}{|c|c|c|c|c|c|c|}
\hline \multirow[b]{2}{*}{$\begin{array}{l}\text { Sample } \\
\text { No }\end{array}$} & \multicolumn{5}{|c|}{ Grey Relation grade } & \multirow[b]{2}{*}{ Rank } \\
\hline & $\begin{array}{l}\text { Bead } \\
\text { Width } \\
(\mathrm{mm})\end{array}$ & $\begin{array}{l}\text { Bead } \\
\text { Height } \\
(\mathrm{mm})\end{array}$ & $\begin{array}{c}\text { Penetration } \\
\text { depth } \\
(\mathrm{mm})\end{array}$ & $\begin{array}{l}\text { Microhardness } \\
\quad(\mathrm{VHN})\end{array}$ & $\begin{array}{c}\text { Combined } \\
\text { GRA } \\
\text { Coefficient }\end{array}$ & \\
\hline 1 & 0.528 & 0.433 & 0.372 & 0.720 & 0.509 & 9 \\
\hline 2 & 0.426 & 0.367 & 0.443 & 0.803 & 0.537 & 6 \\
\hline 3 & 0.386 & 0.367 & 0.396 & 0.615 & 0.456 & 18 \\
\hline 4 & 0.351 & 0.333 & 0.378 & 0.674 & 0.456 & 17 \\
\hline 5 & 0.393 & 0.439 & 0.432 & 0.333 & 0.397 & 20 \\
\hline 6 & 0.416 & 0.390 & 1.000 & 0.606 & 0.703 & 1 \\
\hline 7 & 0.814 & 0.614 & 0.333 & 0.603 & 0.529 & 7 \\
\hline 8 & 0.453 & 0.447 & 0.435 & 0.536 & 0.470 & 16 \\
\hline 9 & 0.830 & 0.783 & 0.335 & 0.663 & 0.575 & 5 \\
\hline 10 & 0.535 & 0.373 & 0.366 & 0.734 & 0.503 & 11 \\
\hline 11 & 1.000 & 1.000 & 0.342 & 0.530 & 0.596 & 3 \\
\hline 12 & 0.333 & 0.353 & 0.440 & 0.773 & 0.511 & 8 \\
\hline 13 & 0.495 & 0.511 & 0.381 & 0.639 & 0.495 & 13 \\
\hline 14 & 0.383 & 0.436 & 0.432 & 0.525 & 0.453 & 19 \\
\hline 15 & 0.459 & 0.620 & 0.403 & 0.611 & 0.506 & 10 \\
\hline 16 & 0.435 & 0.477 & 0.426 & 1.000 & 0.607 & 2 \\
\hline 17 & 0.433 & 0.487 & 0.427 & 0.634 & 0.499 & 12 \\
\hline 18 & 0.409 & 0.407 & 0.450 & 0.631 & 0.492 & 14 \\
\hline 19 & 0.419 & 0.458 & 0.465 & 0.542 & 0.480 & 15 \\
\hline 20 & 0.633 & 0.802 & 0.341 & 0.789 & 0.588 & 4 \\
\hline
\end{tabular}


Table 5. ANOVA for the grey relational grade.

\begin{tabular}{llllll}
\hline Source & DF & Adj SS & Adj MS & F-Value & P-Value \\
\hline Regression & 9 & 0.028882 & 0.003209 & 7.15 & 0.002 \\
$\quad$ Current & 1 & 0.00362 & 0.00362 & 8.07 & 0.018 \\
$\quad$ Standoff Distance & 1 & 0.004658 & 0.004658 & 10.38 & 0.009 \\
$\quad$ Weld Speed & 1 & 0.000028 & 0.000028 & 0.06 & 0.809 \\
$\quad$ Current*Current & 1 & 0.001512 & 0.001512 & 3.37 & 0.096 \\
$\quad$ Standoff Distance*Stan d off & 1 & 0.000816 & 0.000816 & 1.82 & 0.207 \\
$\quad$ Distance & 1 & 0.003745 & 0.003745 & 8.35 & 0.016 \\
$\quad$ Weld Speed*Weld Speed & 1 & 0.008325 & 0.008325 & 18.56 & 0.002 \\
$\quad$ Current*Standoff Distance & 1 & 0.000239 & 0.000239 & 0.53 & 0.482 \\
$\quad$ Current*Weld Speed & 1 & 0.006928 & 0.006928 & 15.44 & 0.003 \\
$\quad$ Standoff Distance*Weld & 1 & 0.004486 & 0.000449 & & \\
Speed & 10 & 0.002639 & 0.000528 & 1.43 & 0.352 \\
Error & 5 & 0.001847 & 0.000369 & & \\
Lack-of-Fit & 5 & 0.033368 & & & \\
Pure Error & 19 & & & & \\
Total & & & & &
\end{tabular}

Main Effects Plot for Grey Relational Grade

Fitted Means

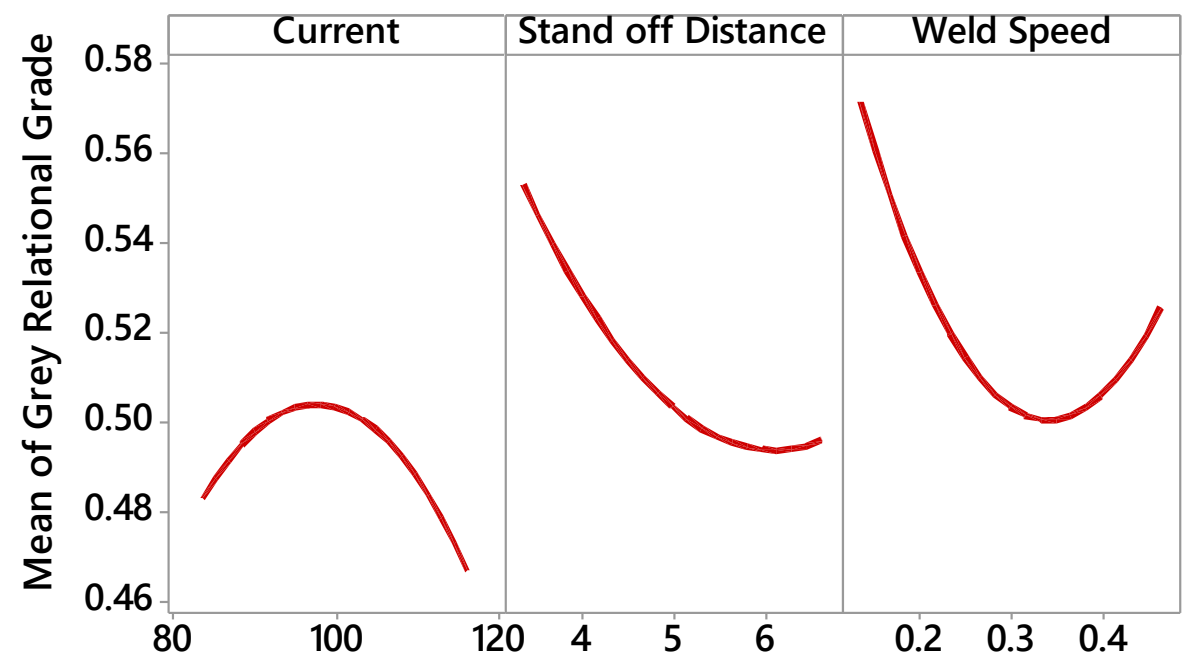

Fig. 4. Grey relational grade response graph. 


\section{Contour Plot of Grey Relational Grade vs Stand off Distance, Current}
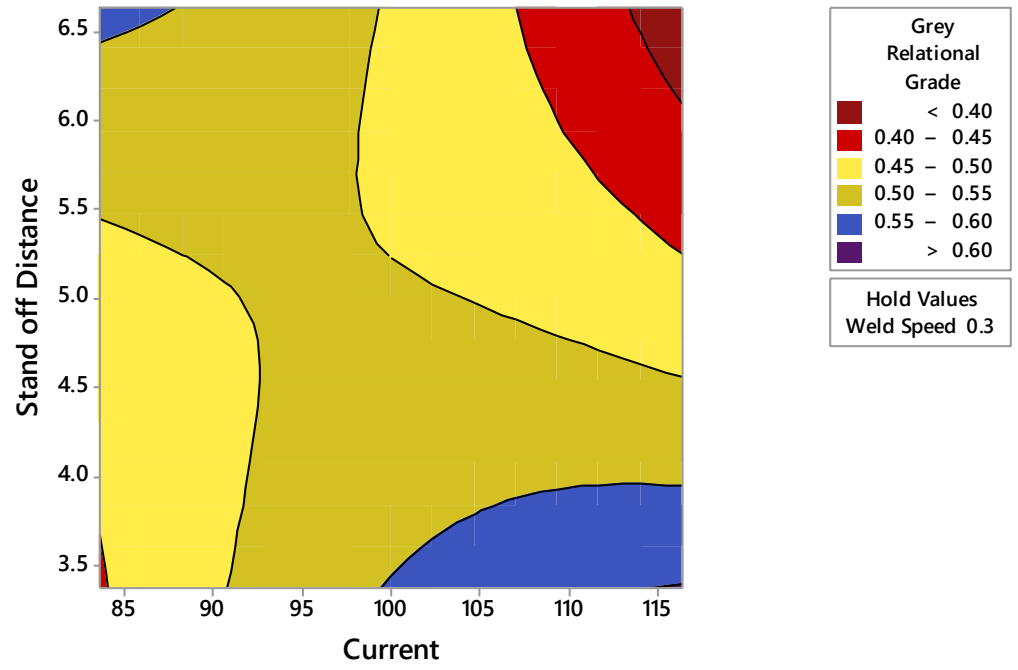

a)

\section{Contour Plot of Grey Relational Grade vs Weld Speed, Current}
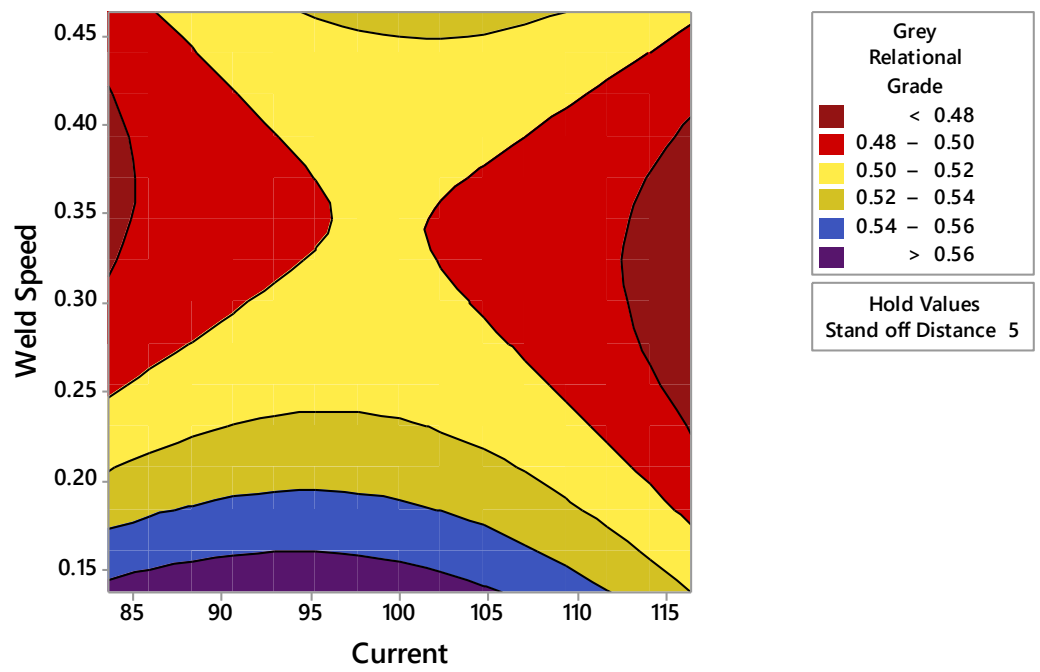

b) 


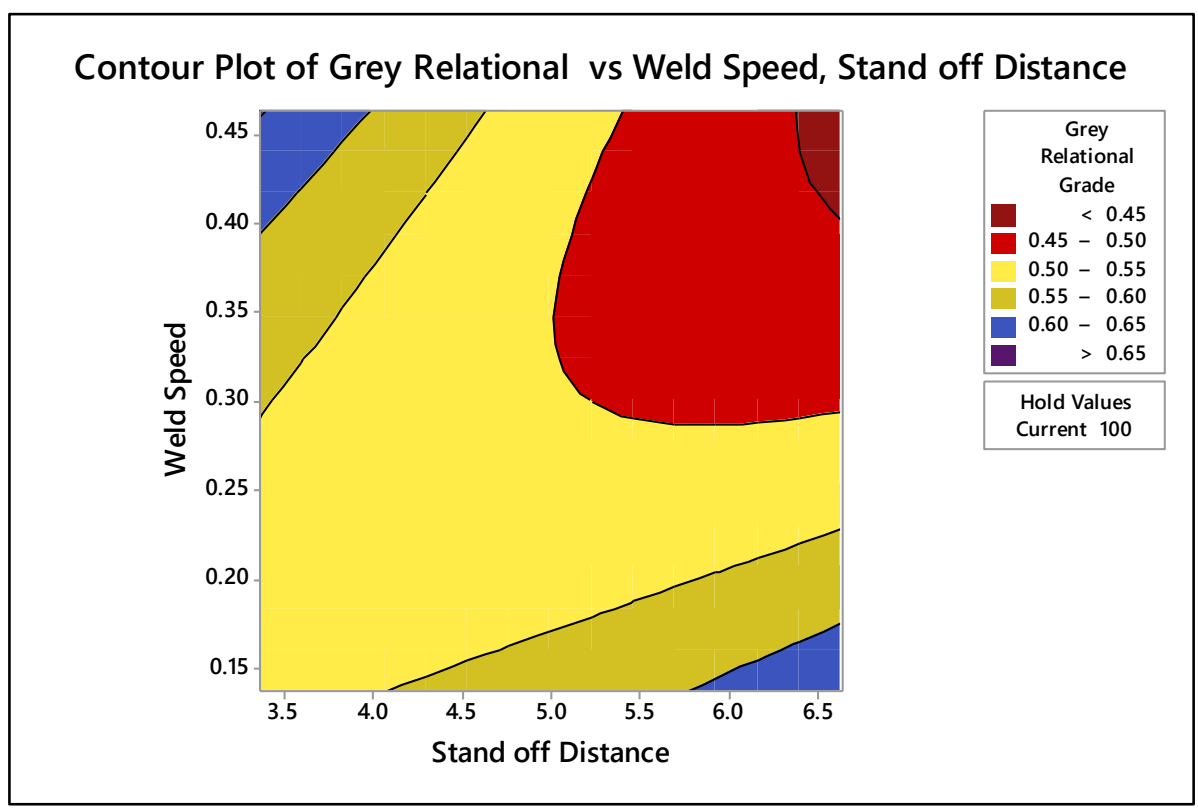

c)

Fig. 5. 2D contours graphs a) current and standoff distance vs. GRG, b) current and weld speed vs. GRG, and c) weld speed and standoff distance vs. GRG.

The main effects plots from the GRG have been depicted in Fig 4. It was obtained by averaging the GRG values at all the levels for each parameter. The maximum peak from the graph indicates that the level has more influence on the combined multi response characteristics. Likewise, from Fig 5 it is obvious that 83.67amps current, standoff distance at $3.367 \mathrm{~mm}$, and weld speed of $0.1367 \mathrm{~mm} / \mathrm{sec}$ have maximum influence on combined response characteristics.

The experimental RSM design with GRG data was analyzed using Minitab software. 2D surface contours have been plotted to analyze the effect of process parameters (current, weld speed, and standoff distance) on calculated GRG from all the responses. Fig 5a shows the effect of current and standoff distance on GRG at a constant weld speed of $0.3 \mathrm{~mm} / \mathrm{sec}$. It is observed from Fig 5a that an increase in current and standoff increases the GRG values, thereby performance characteristics also. Fig5b shows the effect of current and weld speed on GRG at a constant standoff distance of $5 \mathrm{~mm}$. The GRG is noted to decrease with the increase of weld speed and current. Fig 5c shows the effect of weld speed and standoff distance on GRG at a constant current of 100 amperes. It is evident that increasing standoff distance decrease in GRG, and increasing weld speed increases GRG. Analysis of variance (ANOVA) has been performed to study the effect of process parameters on multiple response GRG grades. The ANOVA results are tabulated in Table 6. The results show that the main effects of current, standoff distance, and square terms of current, weld speed, and interaction of current-standoff distance, weld speed-standoff distance are significant at a $95 \%$ confidence level. 


\section{Conclusions}

Grey relational analysis was applied to response surface design experiments to evaluate the multi objective performance of bead characteristics deposited by the cold metal transfer process on a mild steel substrate. A specimen size of $10 \mathrm{~mm} \mathrm{X} 10 \mathrm{~mm}$ is extracted from the substrate to study the bead characteristics The deposition characteristics, namely bead width, bead height, penetration, and microhardness, are considered for the present study. The simultaneous objective of minimum bead width, minimum bead height, maximum penetration depth, and maximum microhardness is observed from the GRA analysis at 100 Amperes current, $5 \mathrm{~mm} / \mathrm{min}$ weld speed, and 0.3 $\mathrm{mm}$ standoff distance. Any specific performance measure can be adjusted so that the other performance metrics satisfy the functional requirements.

For any additive manufacturing process, single beads' deposition and interfacial characteristics are crucial to building the layers in successive depositions. The bead characteristics significantly affect the layer height, surface roughness, and interfacial characteristics. Hence, the multi-objective criteria have to be followed to develop the AM process from the CMT based wire arc deposition process. Further, the present results give an idea of the combined performance of bead deposition characteristics and mechanical strength, which may help the conversion of single bead deposition into a multipass multi track deposition which tends to be an additive manufacturing process.

\section{Acknowledgment}

The authors would like to acknowledge "Welding Research Cell, SVCE, Sri Perumbudur", for their support in the smooth conduction of experiments.

\section{References}

[1] J.F. Wang, Q.J. Sun, H. Wang, J.P. Liu, J.C. Feng: Mater Sci Eng A, 676 (2016) 395-405..

[2] J. Xiong, R. Li, Y. Lei, H. Chen: J Mater Process Technol, 251 (2018) 12-19.

[3] Y. Ma, D. Cuiuri, H. Li, Z. Pan, C. Shen: Mater Sci Eng A, 657 (2016) 86-95.

[4] J. Lin, Y. Lv, Y. Liu, Z. Sun, K. Wang, Z. Li, Y. Wu, B. Xu: J Mech Behav Biomed Mater, 69 (2017) 19-29.

[5] J. Ge, J. Lin, Y. Lei, H. Fu: Mater Sci Eng A, 715 (2018) 144-153.

[6] M. Rsm, C.O. Laser, K.R. Milkey, A.R. Samsudin, A.K. Dubey, P. Kidd, Jordan: J Mech Ind Eng, 8 (2014) 35-42.

[7] Y. Wu, F. Zhou, J. Kong: Comput Ind Eng, 140 (2020) 1062-76.

[8] C.J. Tzeng, Y.H. Lin, Y.K. Yang, M.C. Jeng: J Mater Process Technol, 209 (2009) 2753-2759.

[9] K.S. Prakash, P.M. Gopal, S. Karthik: Measurement, 157 (2020).

[10] B. Rajeswari, K.S. Amirthagadeswaran: Measurement, 105 (2017) 78-86.

[11] H.S. Lu, C.K. Chang, N.C. Hwang, C.T. Chung: J Mater Process Technol, 9 (2008) 3808-3817.

[12] F. Xu, S. Zhang, K. Wu, Z. Dong: Thin-Walled Struct, 131 (2018) 286-296.

[13] S.P. Arun Kumar Srirangan: Eng Sci Technol Int J (2016) 811-817. 
[14] M. Chen, Y. Ho, W. Hsiao, T. Wu, S. Tseng, K. Huang: Opt Lasers Eng, 49 (2011) 222-228.

[15] K.F. Tamrin, Y. Nukman, N.A. Sheikh, M.Z. Harizam: Opt Lasers Eng, 57 (2014) 40-47.

[16] S.P. Shanmugarajan B, Rishabh Shrivastava: Def Technol (2016) 343-350.

[17] L. Kwang, C. Chung, S. Long, H. Feng: J Mater Process Technol, 182 (2007) 107116.

[18] V. Prajapati, J.J. Vora, S. Das, K. Abhishek: J Manuf Process, 54 (2020) 286-300.

[19] Y.S. Tarng, S.C. Juang, C.H. Chang: J Mater Process Technol, 128 (2002) 1-6.

[20] P. Wang, H. Zhang, H. Zhu, Q. Li, M. Feng: J Mater Process Technol, 288 (2021).

[21] E. Shoesmith, G.E.P. Box, N.R. Draper: Stat, 37 (1988) 82.

[22] D. Ju-Long: Syst Control Lett, 1 (1982) 288-294.

\section{(c) (†) Creative Commons License}

This work is licensed under a Creative Commons Attribution 4.0 International License. 